\title{
APLIKASI SPEECH TO TEXT BAHASA INDONESIA KE BAHASA BENGKULU MENGGUNAKAN POCKETSPHINX BERBASIS ANDROID
}

\author{
Dwita Deslianti ${ }^{1}$, Nio Ade Syahputra ${ }^{2}$ \\ ${ }^{1}$ Fakultas Teknik, Universitas Muhammadiyah Bengkulu \\ Jl. Bali PO BOX 118. Telp (0736) 227665, Fax (0736) 26161, Bengkulu 38119 \\ dwitabetrika07@gmail.com \\ ${ }^{2}$ Fakultas Teknik, Universitas Muhammadiyah Bengkulu \\ Jl. Bali PO BOX 118. Telp (0736) 227665, Fax (0736) 26161, Bengkulu 38119 \\ nioadesyahputra@gmail.com
}

\begin{abstract}
Nowadays, Android based smart phones have become a requirement for community because it serves convenience in our daily life one of them is speech recognation developed by Google. By using this feature, users can facilitate in finding the location, articles and whatever we need when we are busy driving just by using our voice. When travelling out of the town we really need a smart phone to acompany us in our way such as to communicate with the local language that we visit. From this problem the writer will discuss about how to develop a Speech to Text application Bahasa Indonesia to Bengkulu language by using Pocketsphinx based on android. The objective of the research is to build a program application Speech to Text application Bahasa Indonesia to Bengkulu language by using Pocketsphinx based on android. The benefit of this research is to help people who are travelling to Bengkulu so that they can communicate by using Bengkulu language.
\end{abstract}

Keywords: Android, Speech to Text, Pocketsphinx

Abstrak - Saat ini smart phone berbasis Android khususnya sudah menjadi kebutuhan masyarakat karena menjanjikan banyak kemudahan sehari-hari salah satunya ialah speech recognition yang dikembangkan oleh perusahaan Google. Dengan fitur seperti ini, pengguna dapat dimudahkan mencari lokasi, artikel dan apapun yang kita butuhkan saat kita sibuk dalam berkendara dengan hanya menggunakan suara kita saja. Saat bepergian keluar kota pun kita sangat memerlukan sebuah smart phone yang mampu mendampingi kita dalam perjalanan semisal untuk melakukan komunikasi dengan bahasa daerah yang kita kunjungi. Dari permasalahan tersebut maka penulis akan membahas bagaimana membangun suatu aplikasi Speech to Text Bahasa Indonesia ke Bahasa Bengkulu Menggunakan Pocketsphinx Berbasis Android. Tujuan penelitian ini adalah membangun sebuah program aplikasi Speech to Text Bahasa Indonesia ke Bahasa Bengkulu Menggunakan Pocketsphinx Berbasis Android Sehingga manfaat dari penelitian ini adalah Dapat membantu ketika sedang bepergian ke kota Bengkulu untuk melakukan komunikasi dengan bahasa Bengkulu.

Kata Kunci: Android, Speech to Text, Pocketsphinx

\section{Pendahuluan}

Bengkulu adalah sebuah provinsi yang mempunyai bermacam-macam bahasa, salah satunya adalah bahasa yang ada di kota bengkulu, bahasa Bengkulu mempunyai logat yang tidak terlalu kental. logatnya hanya terlihat lebih keras bisa juga dibilang kasar padahal sebenarnya logat Bengkulu itu lembut bagi orang bengkulu. Bahasa bengkulu adalah bahasa sehari-hari yang sering digunakan masyarakat kota bengkulu untuk komunikasi.

Akan tetapi bahasa sehari-hari yang digunakan oleh masyarakat kota bengkulu terancam punah dikarenakan banyaknya generasi-generasi muda di kota bengkulu yang cenderung lebih suka melestarikan bahasa gaul dan bahasa asing ketimbang bahasa daerahnya sendiri. Budaya dan nilai-nilai yang berlaku pada anak muda saat ini telah mengenyampingkan bahasa daerah. Tak ada lagi kesadaran bahwa bahasa daerah adalah warisan budaya luhur yang harus dilestarikan.

Dari permasalahan di atas, Penulis merasa perlu mencari solusi agar Bahasa Melayu bengkulu tidak terancam punah dan masih tetap ada. dengan memanfaatkan teknologi yang berkembang pesat maka diambilah salah satu teknologi yang berkembang Saat ini yaitu speech recognition yang dikembangkan oleh perusahaan Google. Dengan fitur ini, pengguna dapat dimudahkan untuk melakukan komunikasi dengan bahasa melayu bengkulu. speech recognition adalah suatu pengembangan teknik dan sistem yang memungkinkan komputer untuk menerima masukan berupa kata yang diucapkan dengan memanfaatkan Pocketsphinx yang 
merupakan library pengenalan ucapan versi mobile.

II. Metode Penelitian

\subsection{Model Pengembangan Sistem}

Rapid

Development prototyping adalah model proses pembangunan perangkat lunak yang tergolong dalam teknik incremental (bertingkat). RAD menekankan pada siklus pembangunan pendek, singkat, dan cepat. RAD bertujuan mempersingkat waktu yang biasanya diperlukan dalam siklus hidup pengembangan sistem tradisional antara perancangan dan penerapan suatu sistem informasi. (Kendall, 2010). '

\subsubsection{Flowchart}

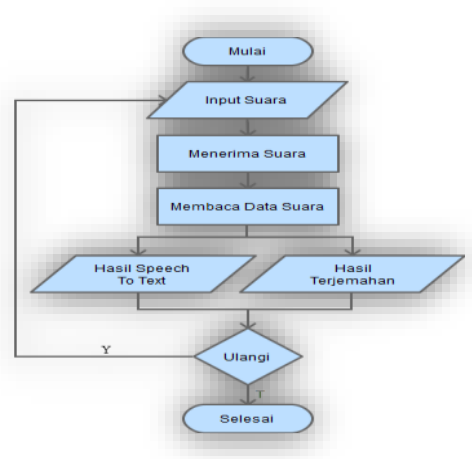

Gambar 2.1 Flowchart Aplikasi

\subsubsection{Struktur Menu}

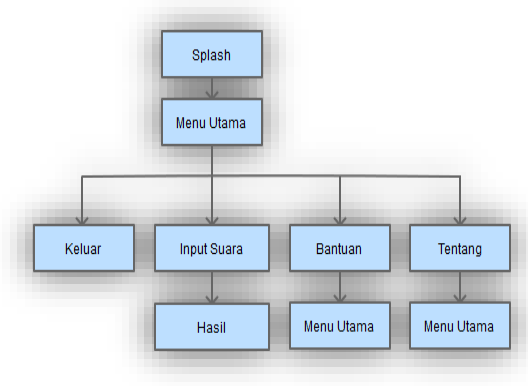

Gambar 2.2 Struktur Menu

\subsubsection{Desain Rancangan}

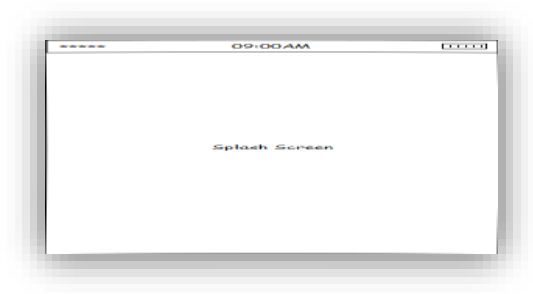

Gambar 2.3 Splash Screen
Ini adalah tampi

lan Splash Screen ketika pertama kali kita menjalankan Aplikasi sebelum menu utama di tampilkan.

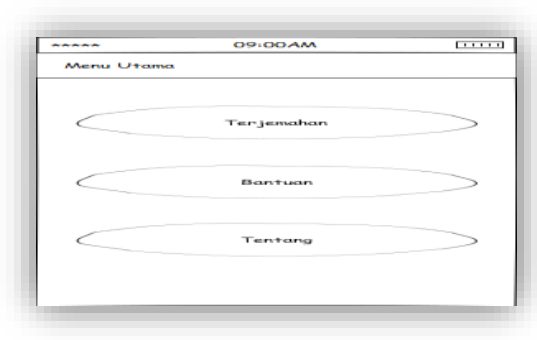

\section{Gambar 2.4 Menu Utama}

Ini adalah tampilan menu utama pada aplikasi Speech to Text Bahasa Indonesia ke Bahasa Bengkulu, di dalam menu ini terdapat menu terjemahan Bahasa Indonesia-Bengkulu, Bantuan dan tentang.

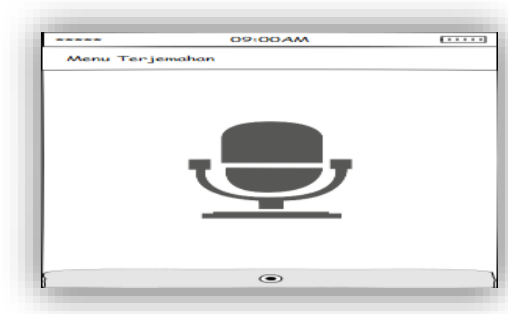

Gambar 2.5 Menu Terjemahan

ini merupakan tampilan dari menu terjemahan ketika menekan tombol Indonesia-Bengkulu, pada menu ini pengguna dapat menerjemahkan bahasa indonesia ke Bahasa Bengkulu dengan cara input suara.

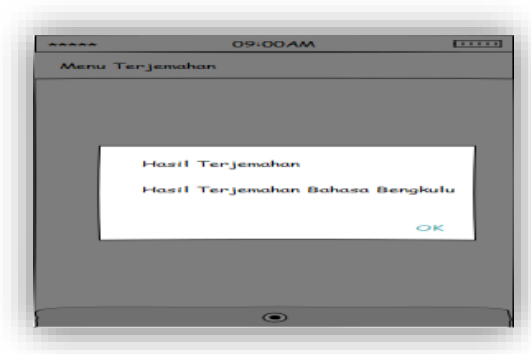

Gambar 2.6 Menu Hasil Terjemahan

Ini adalah tampilan hasil terjemahan IndonesiaBengkulu, menu ini akan muncul secara otomatis ketika kita telah melakukan terjemahan dengan input suara pada menu sebelumnya.

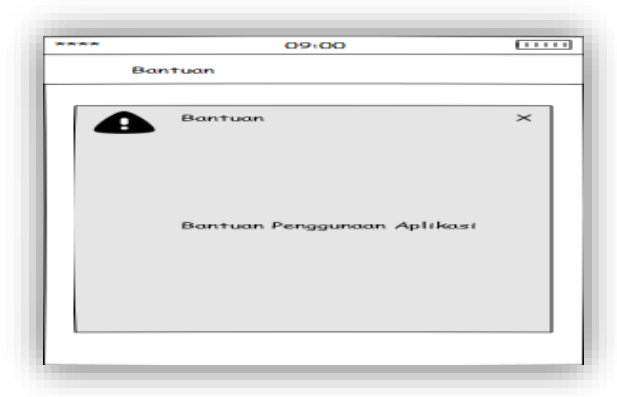

Gambar 2.7 Menu Bantuan 
Menu bantuan Merupakan tampilan menu yang menampilkan keterangan tentang aplikasi dan cara penggunaan aplikasi.

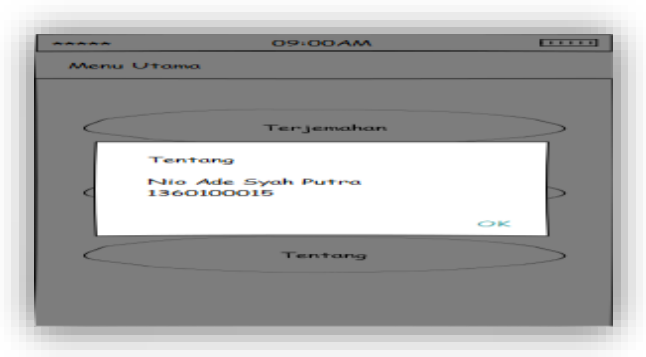

Gambar 2.8 Menu Tentang

\section{Hasil dan Diskusi}

3.1 Hasil

3.1.1Splash Screen

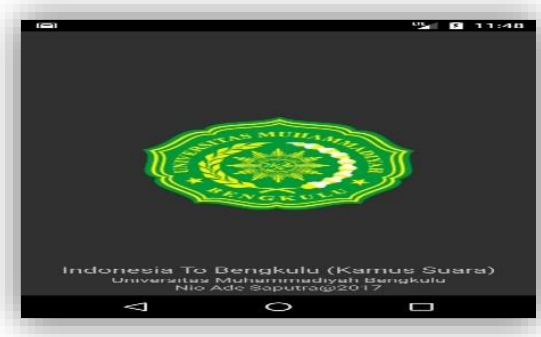

Gambar 3.1 Splash Screen

Ini adalah tampilan Splash Screen ketika pertama kali kita menjalankan Aplikasi.

\subsubsection{Menu Utama}

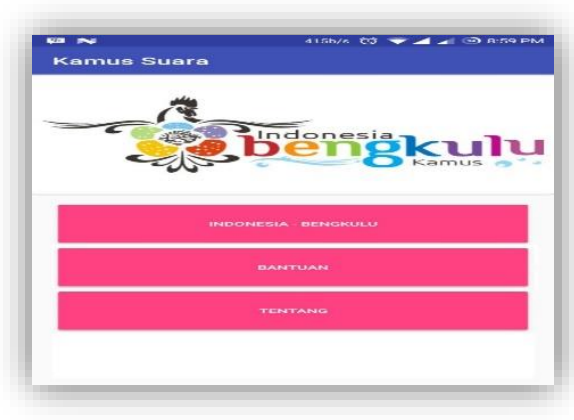

Gambar 3.2 Menu Utama

Ini adalah tampilan menu utama pada aplikasi Speech to Text Bahasa Indonesia ke Bahasa Bengkulu, di dalam menu ini terdapat menu terjemahan Bahasa IndonesiaBengkulu, Bantuan dan tentang.

\subsubsection{Menu Terjemahan}

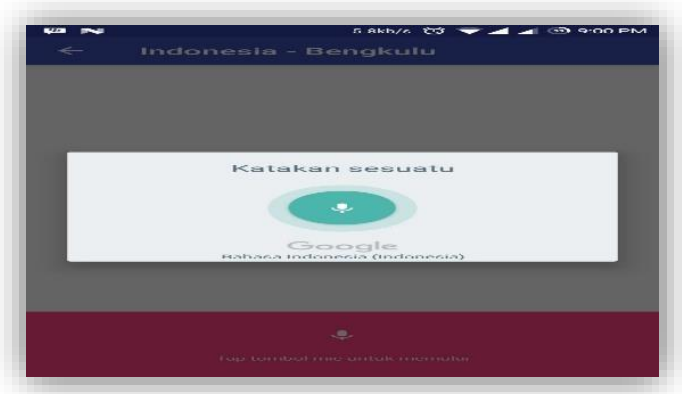

Gambar 3.3 Menu Terjemahan

ini merupakan tampilan dari menu terjemahan ketika menekan tombol Indonesia-Bengkulu, pada menu ini pengguna dapat menerjemahkan bahasa indonesia ke Bahasa Bengkulu dengan cara input suara.

\subsubsection{Menu Hasil Terjemahan}

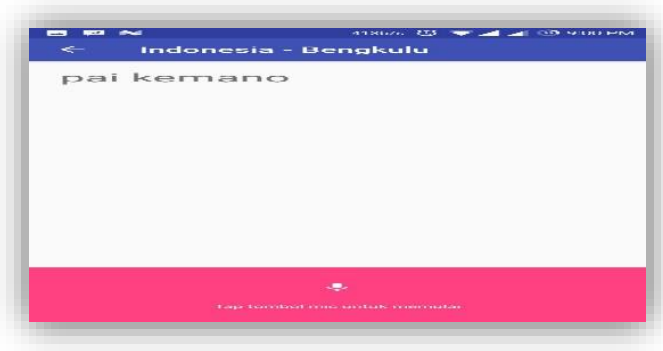

Gambar 3.4 Menu Hasil Terjemahan

Ini adalah tampilan hasil terjemahan Indonesia-Bengkulu, menu ini akan muncul secara otomatis ketika kita telah melakukan terjemahan dengan input suara pada menu sebelumnya.

\subsubsection{Menu Bantuan}

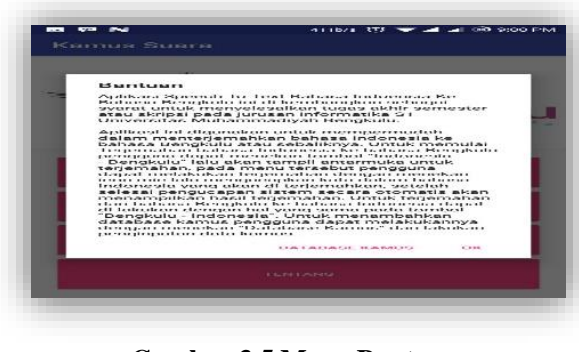

\section{Gambar 3.5 Menu Bantuan}

Menu bantuan Merupakan tampilan menu yang menampilkan keterangan tentang aplikasi dan cara penggunaan aplikasi, di dalam menu bantuan terdapat juga tombol database kamus fungsinya ialah untuk menambah database kamus bahasa Indonesia-Bengkulu yang mungkin belum ada pada sistem. 


\subsubsection{Menu Input Database Kamus}

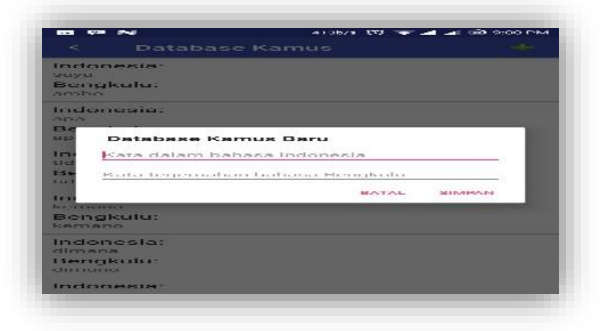

Gambar 3.6 Menu Input Database Kamus

Ini merupakan tampilan dari menu input database kamus yang sebelum nya telah di bahas di Gambar 4.5, pada menu ini pengguna dapat menambahkan kata-kata Bahasa Indonesia dan terjemahannya dalam Bahasa Bengkulu.

\subsubsection{Menu Tentang}

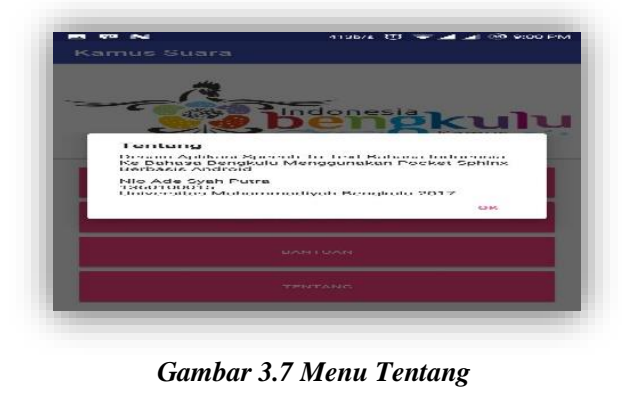

3.2 Diskusi

\subsubsection{Penerapan Pocketsphinx}

Dalam pemrosesannya untuk dapat mengkonversi suara ke dalam bentuk teks terdapat beberapa tahapan, diantaranya:

1. Suara pengguna berupa sinyal analog dikonversi oleh device kedalam bentuk diskrit (karakter dalam abjad) yang kemudian di ubah bentuk kedalam bentuk biner (penulisan angka menggunakan dua simbol 0-1) dan secara Langsung dikirim ke library Pocketsphinx.

2. Setelah pengguna berhenti berbicara (stop recording or end detect) / library Pocketsphinx menerima seluruh data percakapan dalam bentuk digital / biner, kemudian library Pocketsphinx akan melakukan proses konversi.

\subsubsection{Kasus dan Hasil Pengujian}

\subsubsection{Pengujian Confusion Matrix}

- Pengujian dilakukan dengan menggunakan confusion matrix yaitu sebuah matrik dari prediksi yang akan dibandingkan dengan kelas yang asli dari data inputan. Pengujian dilakukan menggunakan 100 kosakata Bahasa Indonesia-
Bengkulu yang diambil secara acak dan sudah diberi label.

IV. Kesimpulan 4.1 Kesimpulan

Dari hasil analisa, perancangan, pengujian dan implementasi program yang telah dilakukan dapat disimpulkan sebagai berikut :

1. Implementasi dari pocketsphinx ke dalam aplikasi speech to text dapat direalisasikan dengan hasil pengenalan yang baik.

2. Aplikasi Speech to Text Bahasa Indonesia ke Bahasa Bengkulu ini dapat membantu pengguna dalam menerjemahkan Bahasa Indonesia ke Bahasa Bengkulu.

3. Dalam sistem pengenalan suara, banyak faktor yang mempengaruhi akurasi. pengucapan bisa pelan ataupun kasar, dan banyaknya kata yang pengucapannya mirip.

\subsection{Saran}

Penelitian yang dilakukan tentunya tidak terlepas dari kekurangan dan kelemahan, maka penulis menyarankan beberapa hal di antaranya :

1. Metode yang digunakan untuk aplikasi speech to text dapat diganti dengan metode lain yang lebih baik lagi dalam mengenali suatu kata.

2. Kedepannya pada sistem ini bukan hanya dapat merubah suatu speech ke text dan menterjemahkannya kedalam text, namun hasil terjemahan dapat kita dengar tidak hanya sebatas text yang terlihat.

\section{Referensi}

[1] Bentley D, Whitten L, Jeffery, Lonnie,Dittman C, Kevin. 2004. Metode Desain dan Analisis Sistem., Andi Offset, Yogyakarta.

[2] Jinyu Li, dkk. 2013. Robust Automatic Speech Recognition, A Bridge to Practical Applications. Academic Press. united states of america.

[3] Kenneth E. Kendall, Julie E. Kendall. 2010. Analisis dan Perancangan Sistem. PT Indeks, Jakarta.

[4] Roger S. Pressman, Ph.D. 2010. Rekayasa Perangkat Lunak: Pendekatan Praktisi. Andi Offset, Yogyakarta.

[5] Taylor dan Paul. 2007. Text-to-Speech Synthesis. United Kingdom: Cambridge University Press.

[6] Pressman, R.S. 2005. Software Engineering: A Practiotioner's Approach, Forth Edition, McGraw-Hill Book, Co. 